\title{
Odds ratios of work related deaths in United States workers
}

\author{
J P LEIGH \\ From the Department of Economics, San Jose State University, San Jose, CA 95192-0114, USA
}

\begin{abstract}
A new data set on job related mortality within 3473 digit occupations is merged with two national probability samples of United States workers to assess which groups are in hazardous and which in safe jobs. Logistic regressions are fitted to the two samples and the following covariates are assumed to explain employment in a hazardous job: age, race, gender, schooling, region, and marital status. Results from both samples are remarkably similar. Odds ratios for non-whites versus whites are roughly $1.2 / 1$; for high school dropouts versus people with some college education roughly $2.2 / 1$; and for men versus women roughly 5.0/1.
\end{abstract}

Injuries are the leading cause of death in the United States from the first year of life to age $44 .^{\prime}$ Accidents are second only to diseases of the circulatory system in total medical economic cost to the United States, accounting for roughly $14 \%$ of total costs. ${ }^{2}$ Yet with the exception of a few studies on vehicular deaths, fatal accidents have received little attention by epidemiologists. The gap in our knowledge is especially great as it pertains to job related deaths. The Bureau of Labor Statistics (BLS) estimates that $13000-15000$ job related deaths occur each year. ${ }^{3}$ Our understanding of the various groups in society who suffer this toll is extremely limited, however. Casual empiricism suggests that men and blacks suffer a disproportionate share of the deaths but no evidence exists in print to verify these speculations. The present study uses a new and unique set of data on occupational mortality to answer the following questions: (1) What groups of workers are at greater risk? and (2) How much greater is the risk because of the jobs they hold? Relative risks for the various groupsfor example, non-whites versus whites, men versus women, will be calculated using coefficient estimates from logistic regression equations.

Data: new estimates of occupational mortality in the United States

Statistics on job related death by occupation are essential to calculate which groups are at greater risk. Yet no nationally based data set for occupational mortality exists in the United States as Baker et al

Accepted 26 January 1987 recently discovered. ${ }^{4}$ What follows is a brief analysis of a new data set on occupational mortality that I recently compiled. A thorough discussion of these data appears elsewhere. ${ }^{5}$

In 1976 the Bureau of Labor Statistics (BLS) began collecting a new set of data from selected states' workers' compensation (WC) files. The data include information on all deaths verified by WC authorities for 3 digit occupations within each of the states. (Examples of 3 digit occupations may be found in tables 1 and 2 and the Dictionary of Occupational Titles.) The deaths represent "closed cases"-that is, WC claims that state WC authorities deemed legitimate job related deaths. Because WC authorities are more likely to recognise accidents than illnesses (with the exception of asbestos induced and, in some cases, radiation induced illnesses) as job related, virtually all the deaths were due to accidents. Hence, the death rates generally reflect safety hazards resulting in death. The raw data are not comprehensive as not all 50 states were included in the analysis. (The 11 included are: Arkansas, Colorado, Delaware, Idaho, Montana, North Carolina, New York, South Carolina, Virginia, Washington, and Wisconsin). Root and Sebastian, nevertheless, have expressed confidence in the data and stated that they are representative of the national United States experience. ${ }^{6}$ On request, the BLS made data on deaths within 1970 census 3 digit occupations for 1977, 1978, 1979, and 1980 available for study. Attention was restricted to fatalities so that less precise medical diagnoses such as job related back pain could be ignored.

The calculation for the annual probability of death (OCCDTH) within each occupation is straightforward. By example one can consider a typical 3 digit 
occupation such as statisticians. OCCDTH for these workers is calculated as follows:

$$
\text { OCCDTH }=\frac{\sum_{t=1977}^{1980} \sum_{i=1}^{I_{t}} \text { FATAL }_{i t}}{\sum_{t=1977}^{1980} \sum_{i=1}^{i_{t}} \text { EMP }_{i t}}
$$

where FATAL ${ }_{\mathrm{it}}$ is the number of fatalities for statisticians in the $\mathrm{i}^{\text {th }}$ state in the $\mathrm{t}^{\text {th }}$ year; $\mathrm{EMP}_{\text {it }}$ is the full time employment for these workers in the $\mathrm{i}^{\text {th }}$ state in the $\mathrm{t}^{\text {th }}$ year. The FATAL numbers are from the BLS study described in Root and Sebastian. ${ }^{6}$ The index " $I$ " itself varies from year to year since information on FATAL from only selected states is available and the states differ from year to year. For example, eight states are included in 1979 but only six in 1978. The EMP numbers were obtained from state annual occupational employment data in various BLS publications including Distribution of Occupational Employment in States and Areas ${ }^{7}$ and State Profile of Employment and Unemployment ${ }^{8}$ and unpublished tables available from the BLS. Four years of data on deaths rather than one year were used to allow for greater variation in OCCDTH. In any one year a disproportionate number of occupations, especially those with few workers, had no deaths.

Tables 1 and 2 present estimates of the annual probability of job related death for the 20 jobs with the highest death rates. Table 1 provides the numbers for blue collar and service workers and table 2 for white collar and clerical jobs. The data can be easily understood. The number 0.0012909 for loggers means that the average logger faces roughly a 13 out of 10000 annual chance of dying in the line of work.

In longer versions of tables 1 and 2 in which 347 occupations are described many rates are zero. (Longer versions are available in Leigh. ${ }^{5}$ ) Out of 347 occupations, there are 52 zero probabilities in the blue collar group and 84 in the white collar group. These zero probabilities should be interpreted with great caution. Although the occupations at the bottom of the table such as teachers and clerical workers do appear intuitively to be less hazardous than those at the top, some of these may have zero probabilities simply because of insufficient data available in the BLS statistics. Deaths are rare. When the population considered is large - for example, for truck drivers several deaths will occur. When the population considered is small - for example, fishermen-a single death may not occur within a year, especially within only a few states. Death rates are more reliable for occupations with many employees than for those with few employees. Fishing, particularly ocean fishing, is dangerous as British data from Marin and Psacharopoulos indicate. ${ }^{9}$ The mortality rate for fishermen in a longer version of table 1 , available in Leigh, ${ }^{5}$ wrongly implies that fishing is safe because not enough data were available properly to assess the death rate in this occupation with so few members.

Table 1 Blue collar and service death rates, 1976-80

\begin{tabular}{|c|c|c|c|c|}
\hline $\begin{array}{l}1970 \text { Census } \\
\text { occupation } \\
\text { No }\end{array}$ & Description & $\begin{array}{l}\text { No of } \\
\text { fatalities }\end{array}$ & $\begin{array}{l}\text { Total } \\
\text { employment } \\
(1000 \text { s })\end{array}$ & $\begin{array}{l}\text { Annual } \\
\text { probability } \\
\text { of death }\end{array}$ \\
\hline $\begin{array}{l}761 \\
601 \\
550 \\
433\end{array}$ & $\begin{array}{l}\text { Timber cutting and logging workers } \\
\text { Asbestos and insulation workers } \\
\text { Structural metal workers } \\
\text { Electric power line and cable installers } \\
\text { and repairers }\end{array}$ & $\begin{array}{l}71 \\
26 \\
31 \\
32\end{array}$ & $\begin{array}{l}55 \\
33 \\
43 \\
63\end{array}$ & $\begin{array}{l}0.0012909 \\
0.00078788 \\
0.00072093 \\
0.00050794\end{array}$ \\
\hline $\begin{array}{l}961 \\
754 \\
715 \\
640 \\
751\end{array}$ & $\begin{array}{l}\text { Fire fighters } \\
\text { Garbage collectors } \\
\text { Truck drivers } \\
\text { Mine operators, nec } \\
\text { Construction labourers excl } \\
\text { carpenters' helpers }\end{array}$ & $\begin{array}{r}66 \\
16 \\
430 \\
48 \\
159\end{array}$ & $\begin{array}{r}135 \\
40 \\
1085 \\
128 \\
474\end{array}$ & $\begin{array}{l}0.00048889 \\
0.00040000 \\
0.00039631 \\
0.00037500 \\
0.00033544\end{array}$ \\
\hline $\begin{array}{l}503 \\
436 \\
424 \\
964 \\
402 \\
502 \\
662 \\
480 \\
520 \\
540 \\
633\end{array}$ & $\begin{array}{l}\text { Moulders, metal } \\
\text { Excavating, grading, road machine operators } \\
\text { Crane, derrick, and hoist operators } \\
\text { Police and detectives } \\
\text { Bakers } \\
\text { Millwrights } \\
\text { Sawyers } \\
\text { Farm implement } \\
\text { Plasters } \\
\text { Shipfitters } \\
\text { Meatcutters and butchers' manufacturing }\end{array}$ & $\begin{array}{r}8 \\
51 \\
17 \\
51 \\
12 \\
9 \\
13 \\
5 \\
2 \\
1 \\
9\end{array}$ & $\begin{array}{r}30 \\
243 \\
88 \\
291 \\
71 \\
58 \\
84 \\
35 \\
14 \\
7 \\
65\end{array}$ & $\begin{array}{l}0.00026670 \\
0.00020988 \\
0.00019318 \\
0.00017526 \\
0.00016901 \\
0.00015517 \\
0.00015477 \\
0.00014286 \\
0.00014286 \\
0.00014286 \\
0.00013846\end{array}$ \\
\hline
\end{tabular}

*To provide easier interpretation, multiply each probability of death by 10000 . The number for asbestos workers thus becomes $7 \cdot 8$ out of 10000 which means roughly 8 of 10000 asbestos workers die during the year as result of job hazards. nec $=$ Not elsewhere classified. 
Table 2 White collar and clerical death rates, 1976-80

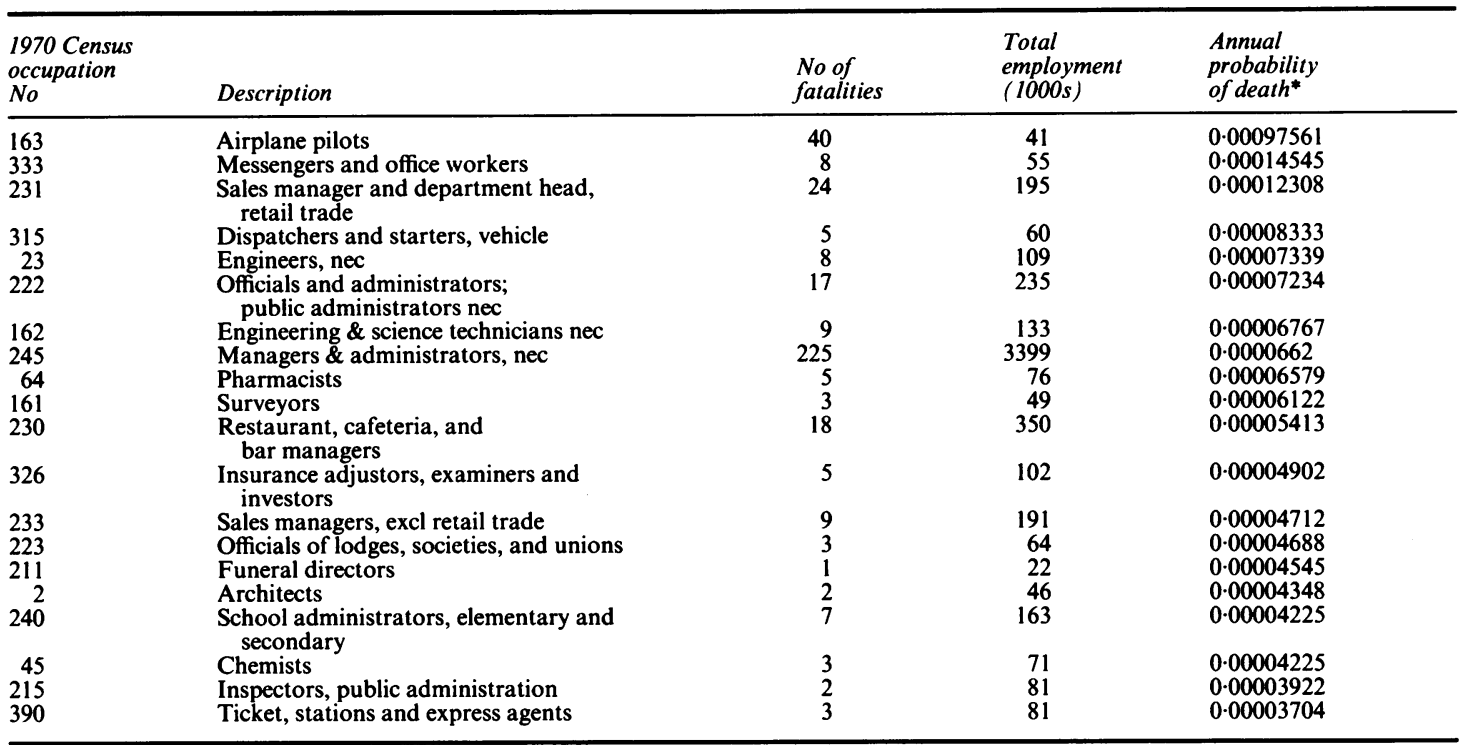

*To provide easier interpretation, multiply each probability by 10000 . The number for pilots thus becomes $9 \cdot 7$ which means roughly 10 out of 10000 pilots die during the year as a result of job hazards. nec $=$ Not elsewhere classified.

One anecdotal and three systematic tests were conducted on the data to determine their reliability. In the anecdotal test the 20 highest mortality jobs in Britain were compared with those in tables 1 and 2 . Marin and Psacharopoulos recently published data from Britain on occupational mortality. ${ }^{9}$ Unfortunately, most of the definitions of occupations differ across the Atlantic. Nevertheles, with the exception of fishing, every occupation in Marin and Psacharopoulos's "top 20" which has an identical United States definition is in the "top 20" in tables 1 and 2. Thus linesmen, pilots, coal operatives, construction workers, and firefighters are high on both lists.

Anecdotal data are never very convincing, however. Three more systematic attempts to verify the reliability of the data were conducted using the University of Michigan's Quality of Employment Survey for 1972-3 (QES). The QES was constructed from a national probability sample. Roughly 1500 subjects aged 16 and over who were working for pay for 20 or more hours a week were interviewed in 1972-3. Many questions were asked concerning the respondent's job. Each respondent was asked, for example, to identify his or her 3 digit occupation. The QES has been widely used by social science researchers (see, for example, Leigh and Folsom. ${ }^{10}$ )

OCCDTH numbers were assigned to each individual depending on the person's 3 digit occupa- tion. The OCCDTH numbers so assigned are then used in the subsequent analysis.

For purposes of measuring the reliability of the 347 occupational death rates in complete versions of tables 1 and 2, three questions asked by QES investigators appear especially useful. The first deals with absenteeism. The respondents were asked whether they had been absent from work during the past two weeks. A large share, if not most, of these absences were due to respondents' medical problems. In an investigation of the determinants of absenteeism Allen found that a regressor (or covariate) which had one of the largest $t$ statistics was the variable measuring the accident rate in the individual's industry. " Thus is appears that hazardous conditions should be associated with absenteeism.

Six regressions were run with the absenteeism variable on the left hand side and the probability of fatality numbers in tables 1 and 2 (OCCDTH) on the right hand side together with a variety of control variables such as age, race, sex, and years of schooling. Each regression attempted produced a large positive estimated coefficient on OCCDTH with a $t$, typically, well over 2 . The first column of table 3 provides a typical example of the regressions attempted.

The second question pertains to the dangerous working conditions perceived by the individual. If DANGER equals 1 the individual reported that he perceived his job to be dangerous. DANGER has been 
Table 3 Multiple regression (OLS) results explaining absenteeism, DANGER and MADEWORSE

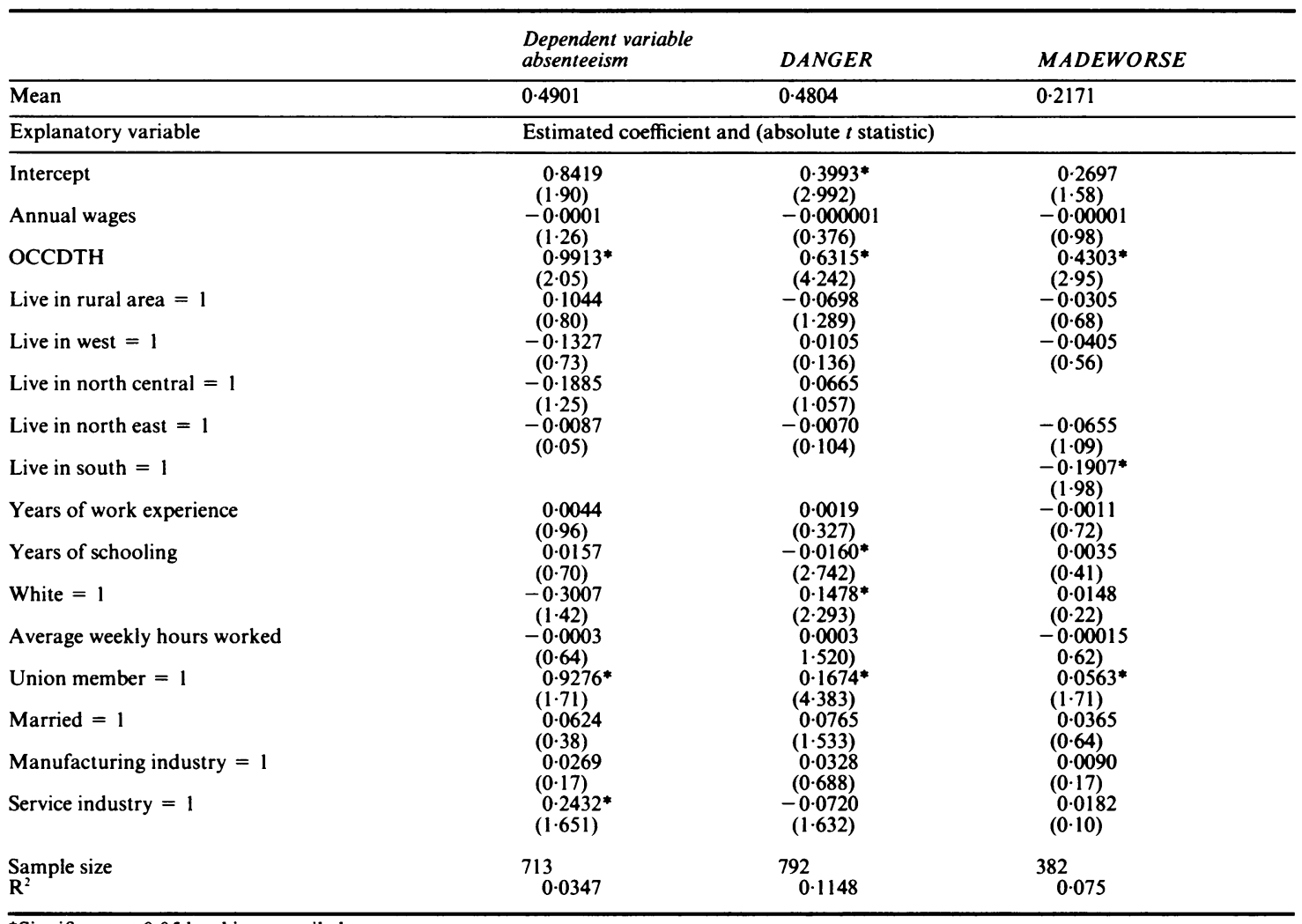

*Significant at $0 \cdot 05$ level in one tailed test

successfully used by Viscusi as a job disamenity variable requiring compensating wages for blue collar workers. ${ }^{12}$ Eleven regressions were run explaining DANGER in which OCCDTH was one of the regressors. In every case the estimated coefficient of OCCDTH was positive and significant at the 0.01 level in a 2 tailed test. An example of one of these 11 regressions appears in the second column of table 3 . Because these regressions were run only to enhance the credibility of the OCCDTH numbers, multiple regression (OLS) was used rather than logistic regression for cost reasons. Finally, the simple correlation coefficient between OCCDTH and DANGER achieved a level of significance better than 0.0001.

A final question was asked pertaining to whether some conditions on the job made a respondent's existing illness or injury worse. The variable MADEWORSE equalled 1 for people responding yes and 0 for those responding no. MADEWORSE was again entered as a dependent variable in a variety of regressions which included the controls mentioned above. The results were as expected. The estimated coefficient on OCCDTH was positive and in most cases the corresponding $t$ statistic was larger than any other $t$ statistic for any other explanatory variable and significant at better than the 0.01 level in a two tailed test. One example appears in table 3. Again, OLS rather than logistic was used.

Workers' compensation fatality numbers were carefully collected and OCCDTH mortality ratios were carefully computed. The evidence above suggests that OCCDTH is apparently strongly related to absenteeism, perception of the job as being dangerous, and whether the worker thinks conditions at the job have worsened existing medical problems. Together, these observations imply that the OCCDTH numbers are reliable indicators of occupational mortality in the United States.

Data: panel study of income dynamics and quality of employment survey

To determine which groups of workers take hazardous and which take safe jobs, the OCCDTH estimates 
were combined with national data on individual full time workers. Two data sets which appear to be especially well suited to assess relative risks are the University of Michigan's Panel Study of Income Dynamics for 1974 (PSID) and Quality of Employment Survey for 1973 (QES). Since both data sets have been widely used (and held to be reliable) by social scientists only a brief description of each will follow. The interested reader is referred to Allen ${ }^{11}$ and Leigh and Folsom ${ }^{10}$ for recent economic applications.

Some readers might object that since the data on OCCDTH are from 1977-80 and those from the PSID and QES are from 1974 and 1973, any analyses merging them would be suspect. There is evidence that industrial accident and illness rates were relatively stable during the 1970s however. The BLS annually publishes accident and illness rates in roughly 300 industries (not occupations). ${ }^{13}$ Whereas the industry data are not useful in calculating relative risks because occupations are not identified they are useful in establishing the stability of rates over the years. The correlation coefficients between data from either 1977 , 1978,1979 or 1980 , and 1974 or 1973 exceed 0.9.

The first survey data set used is the 1973 QES, ${ }^{14}$ a random sample of those working 20 hours or more a week in the United States, conducted by the University of Michigan's Survey Research Center (Inter-University Consortium for Political and Social Research, 1979). QES investigators asked 900 questions of 1515 workers and is considered a rich source of information available about working conditions.

The second set of data is the year 1974 of the Panel Study of Income Dynamics (PSID), ${ }^{15}$ a continuing survey of about 6000 individuals reinterviewed on an annual basis, also conducted by the University of Michigan's Survey Research Center (Institute for Social Research, 1976). 1974 was used as it is the only year in which the 3 digit occupation code was included. The PSID is a random sample of the entire adult United States population, not only of the workforce, therefore a great many respondents are excluded from the sample for present purposes as they are students, retirees, etc. The available sample size is roughly four times that available in the QES.

Each respondent was assigned an OCCDTH number depending on his or her 3 digit occupation. The individual's OCCDTH number will be taken as the dependent variable in the analyses that follow. Individuals who had missing values on any of the variables, including age, race, gender, as well as 3 digit occupation or who were not employed were excluded from the analysis. The QES sample was thus reduced to 1257 and the PSID to 3868 .

\section{Method}

Maximum likelihood logistic regression is used to explain the individual's OCCDTH number. OCCDTH ranges in values from 0 to 0.0012909 . All 347 occupations were used, not just the 40 in tables 1 and 2 . Independent variables include age, race, gender, region, marital status, and years of schooling. The logistic model is used in lieu of multiple regression for two reasons. Multiple regression assumes that the dependent variable is approximately normally distributed and that the dependent variable is not truncated at any particular value. OCCDTH, clearly, does not have either of these characteristics. OCCDTH is truncated at zero and, theoretically, at 1 since a probability cannot exceed 1 . If multiple regression were used to explain OCCDTH predicted values for the dependent variable, OCCDTH, may well lie outside the $0-1$ range. This possibility is illustrated in fig 1 where a straight line, the assumption of multiple regression, is used to fit the data. As may be seen, portions of this line are above and below the limit values of 0 and 1 . Logistic regression, on the other hand, assumes a curve like that displayed in fig 2 . Because of its construction, logistic predicted values on OCCDTH cannot lie outside the $0-1$ range.

The second advantage of logistic regression involves the statistical property of efficiency. When multiple regression is used on truncated dependent variables, heteroskedasticity results ${ }^{16}$ Heteroskedasticity is a statistical disease that afflicts the error term in multiple regression which results in imprecise parameter estimates. Specifically, heteroskedasticity produces standard errors for estimated coefficients that are too large. When standard errors are too large, the model producing them is said to be inefficient. ${ }^{16}$ Logistic regression, because of its construction and explicit

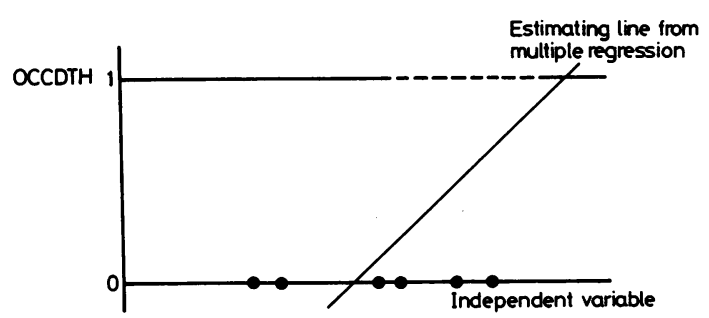

Fig 1 Multiple regression.

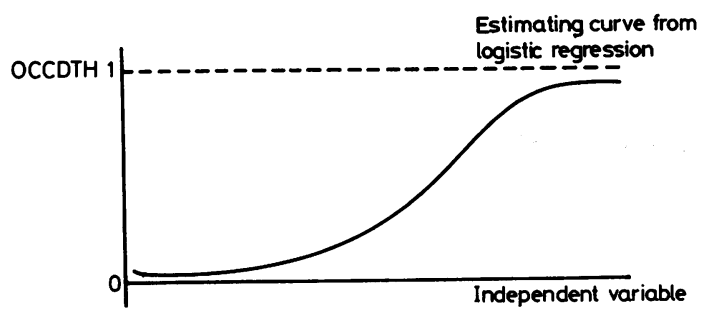

Fig 2 Logistic regression. 
account of truncation, does not suffer from heteroskedasticity. Logistic is efficient whereas multiple regression is not for variables such as OCCDTH.

The logistic may be written as follows:

$$
\mathrm{p}_{\mathrm{i}}=\frac{1}{1+\exp -\left(\alpha+\beta \mathrm{x}_{\mathrm{i}}\right)}
$$

where $\mathrm{p}$ is the probability of job related death, $\alpha$ is a constant term, $X$ is a vector of independent variables, $\beta$ is a coefficient vector, and $\mathrm{i}$ is an index for each person. The SAS maximum likelihood routine which is relied on in this study iterates on various estimates of $\alpha$ and $\beta$ to maximise the likelihood function. The fact that the probability will sometimes be zero does not create any problems for the maximum likelihood routine since the computer merely maximises a function for $\hat{\alpha}$ and $\hat{\beta}$ (the estimates of $\alpha$ and $\beta$ ) rather than solves "closed form" equations which would be required for the multiple regression approximation to the logistic. The multiple regression approximation to the logistic in which the logs-of-the-odds is regressed on the independent variables is inappropriate here since the log of zero is undefined. Odds ratios will be calculated using the estimated coefficients from the multiple logistic equations as explained below.

\section{Results}

Table 4 presents the results from logistic regression equations explaining the worker's OCCDTH. The independent variables are entered into the equations as binary variables so that odds ratios may be directly calculated from regression coefficients.

The mean for the dependent variable is a little bigger in the PSID sample, probably because the PSID oversamples the poor who tend to hold more hazardous jobs than the rich.

The results suggest that age is not a factor in assessing who is employed in hazardous jobs. None of the age variables achieves statistical significance at any conventional level.

Years of schooling, on the other hand, is a powerful predictor of job choice. Both estimated coefficients are significant at better than the 0.005 level $(t=2.58$ for 0.005 level).

The data suggest that whites hold safer jobs than blacks. The estimated coefficients in both samples are significant at better than the 0.05 level of significance in a two tailed test.

Similarly intuitive results are obtained for gender. The coefficient on the male dummy variable is strongly significant and positive, implying that men are in more hazardous jobs than women, other things, such as education, being equal.

The reader will notice that no variable is entered for
Table 4 Logistic regression results explaining $O C C D T H$

\begin{tabular}{|c|c|c|}
\hline & \multicolumn{2}{|c|}{$\begin{array}{l}\text { Means, estimated coefficient, } \\
\text { and (asymptotic } \\
t \text { statistic) }\end{array}$} \\
\hline & $Q E S$ & PSID \\
\hline $\begin{array}{l}\text { Mean OCCDTH } \\
\text { Range }\end{array}$ & $\begin{array}{l}0.00006077 \\
0 \text { to } 0.00129\end{array}$ & $\begin{array}{c}70.00008819 \\
0 \text { to } 0.00129\end{array}$ \\
\hline Independent variables: & & \\
\hline Intercept & $\begin{array}{l}12 \cdot 1763^{*} \\
(6 \cdot 02)\end{array}$ & $\begin{array}{l}10 \cdot 5162^{*} \\
(12 \cdot 716)\end{array}$ \\
\hline $\begin{array}{l}\text { If years of schooling } \leqslant 11 \text { then } \\
\mathrm{SCH} 11=1 \text {, otherwise }\end{array}$ & $0.7794^{*}$ & $0.9063^{*}$ \\
\hline SCH11 = 0 & $(6 \cdot 554)$ & $(4 \cdot 4512)$ \\
\hline $\begin{array}{l}\text { If } 12 \leqslant \text { years of schooling } \leqslant 13 \text { then } \\
\text { SCH } 12=1 \text {, otherwise }\end{array}$ & $0.5491^{*}$ & $0.6156^{*}$ \\
\hline $\begin{array}{l}\text { SCH12 }=0 \\
\text { If years of schooling } \geqslant 14 \\
\text { omitted category }\end{array}$ & $(5 \cdot 708)$ & (3.3099) \\
\hline $\begin{array}{l}\text { If age } \leqslant 34 \text { then AGE30 }=1 \text {, } \\
\text { otherwise }=0\end{array}$ & $\begin{array}{c}0.3517 \\
(0.6152) \\
-0.0712\end{array}$ & $\begin{array}{c}0.2275 \\
(0.6152) \\
-0.1156\end{array}$ \\
\hline $\begin{array}{l}\text { If } 35 \leqslant \text { age } \leqslant 50 \text { then } \\
\text { Age } 40=0, \text { otherwise }=0 \\
\text { If age } \geqslant 51 \text {, } \\
\text { omitted category }\end{array}$ & $\begin{array}{r}-0.0712 \\
(0.3219)\end{array}$ & $\begin{array}{r}-0.1156 \\
(0.2876)\end{array}$ \\
\hline Non-white $=1$, white $=0$ & $\begin{array}{l}0 \cdot 2002^{*} \\
(2.657)\end{array}$ & $\begin{array}{l}0 \cdot 1826^{*} \\
(1.9887)\end{array}$ \\
\hline Male $=1$, female $=0$ & $\begin{array}{l}1.6797^{*} \\
(17.948)\end{array}$ & $\begin{array}{l}1.5728^{*} \\
(14 \cdot 262)\end{array}$ \\
\hline West $=1$, otherwise $=0$ & $\begin{array}{c}-0.0215 \\
(0.3715)\end{array}$ & $\begin{array}{c}0.1297 \\
(0.0727)\end{array}$ \\
\hline North central $=1$, otherwise $=0$ & $\begin{array}{c}0.0359 \\
(0.2016)\end{array}$ & $\begin{array}{r}-0.0013 \\
(0.1502)\end{array}$ \\
\hline North east $=1$, otherwise $=0$ & $\begin{array}{l}0.1719 \\
(1.729)\end{array}$ & $\begin{array}{c}0.5237 \\
(0.8821)\end{array}$ \\
\hline Married, spouse present $=1$ & $\begin{array}{c}0 \cdot 1012 \\
(0.980)\end{array}$ & $\begin{array}{c}0.2613 \\
(0.9231)\end{array}$ \\
\hline Widow $=1$ & $\begin{array}{r}0.2080 \\
(0.769)\end{array}$ & $\begin{array}{c}0.0176 \\
(0.2259)\end{array}$ \\
\hline $\begin{array}{l}\text {-2Ln (likelihood) } \\
\text { level of significance of likelihood } \\
\text { Sample size }\end{array}$ & $\begin{array}{c}212 \cdot 17 \\
0 \cdot 0001 \\
1266\end{array}$ & $\begin{array}{c}240 \cdot 88 \\
0 \cdot 0001 \\
3868\end{array}$ \\
\hline
\end{tabular}

*Significant at 0.05 level in two tailed test.

southern residence. If a "south" dummy variable were added to the equation perfect multicollinearity would result and the equation could not be estimated (see ${ }^{16}$, chapter 13). No region variable achieves significance, however.

Finally, marital status apparently has no effect on holding a hazardous or safe job, other things being equal.

The advantage of logistic regression is that it allows a straightforward calculation of relative risks while simultaneously holding constant many other factors influencing who is employed in a hazardous or safe job. Direct adjustment may also produce relative risks, but direct adjustment, which does not rely on a model, can rarely adjust for more than three factors. ${ }^{17}$ Logistic adjustment, on the other hand, may account for many more independent variables simultaneously. ${ }^{17}$ For a recent example of the procedure involving the relative risks of different age groups and obesity for abnormal $R$ waves see Wilcosky and Lloyd Chambless. ${ }^{17}$ 
Table 5 presents odds ratios estimated from logistic regression coefficients as explained in footnotes a and $\mathrm{b}$ to the table. Odds ratios for only statistically significant coefficients are calculated since odds ratios for insignificant coefficients will yield confidence intervals with lower bounds below 1 .

The largest odds ratios appear to be for gender. The point estimates are 5.3639 in the QES and 4.820 in the PSID. Men face roughly five times the risk of job related death compared with women, holding other covariates such as race, schooling, and marital status constant.

The next largest ratios are for the comparison between high school drop outs ( $\mathrm{SCH} \leqslant 11)$ and subjects with 14 or more years of schooling ( $\mathrm{SCH} \geqslant$ 14) - that is, those with some college experience. High school drop outs hold jobs a little over roughly twice as dangerous as people who have had some college training. A comparison of high school graduates $\mathbf{S C H}$ $=13$ or 14) with subjects with some college experience $(\mathrm{SCH} \geqslant 14)$ found a similar pattern. High school graduates are at a little under twice the risk of job related death when compared with people with some college experience, again, holding other influences such as race, gender, and marital status constant.

Finally, a race disparity is also apparent. Nonwhites are employed in jobs which are, on average, $20 \%$ more hazardous than the jobs held by whites, other things being equal.

\section{Conclusion}

No published account of exposure to job related fatal hazards for various groups of workers exists in the United States. The purpose of this study was to take a small step toward eliminating this gap in our knowledge. New data on occupational mortality was combined with information from two large national United States samples of workers to assess which

Table 5 Odds ratios calculated from logistic regression coefficients*†

\begin{tabular}{|c|c|}
\hline \multirow[b]{2}{*}{ Comparison groups } & $\begin{array}{l}\text { Odds ratio and } \\
(95 \% \text { confidence interval) }\end{array}$ \\
\hline & $P S I D$ \\
\hline Non-white/white & $\begin{array}{cl}1.2214 & 1.2003 \\
(1.0537-1.4161)(1.0026-1.4370)\end{array}$ \\
\hline Male/female & $\begin{array}{cc}5.3639 & 4.8201 \\
(4.4651-6.4437)(3.8833-5.9831)\end{array}$ \\
\hline $\begin{array}{l}\text { Schooling } \leqslant 11 / \text { schooling } \geqslant 14 \\
12 \leqslant \text { schooling } \leqslant 13 / \text { schooling } \geqslant 14\end{array}$ & 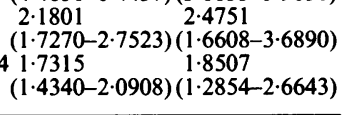 \\
\hline
\end{tabular}

*Point estimates for odds ratios are calculated from the formula: exp $(\hat{\beta})$ where $\hat{\beta}$ is estimated logistic coefficient.

tInterval estimates are calculated from the formula: $\exp (\hat{\beta}+1.96 \mathrm{SE})$ where $\mathrm{SE}$ is the standard error for $\hat{\beta}$. individuals were more inclined to be employed in a hazardous job. Estimated multiple logistic regression coefficients were used to calculate odds ratios while holding constant the influence of various other variables.

The results from the data sets were remarkably similar. As expected, individuals with more education, whites, and women hold a disproportionate number of safe jobs. The gender disparity was particularly striking, with men being employed in jobs which were, on average, five times as dangerous as jobs held by women.

\section{Appendix}

DESCRIPTION OF THE SUPPLEMENTARY DATA SYSTEM (WRITTEN BY ANALYSTS AT THE BLSS not BY THE AUTHOR)

The Bureau of Labor Statistics Supplementary Data System (SDS) is a comprehensive effort to standardise occupational injury and illness data from state workers' compensation information to achieve some degree of comparability. The SDS data are unique in the detail available, providing analysts with opportunities for more extensive research than heretofore possible.

\section{Background}

While the annual survey program provided the information required by the Occupational Safety and Health (OSH) Act of 1970, there was an increasing demand for information about the characteristics of the occupational injuries and illnesses and the workers to whom they were occurring. In 1973, in response to this demand, the bureau began testing the feasibility of collecting such information through contracts with states.

Records routinely generated by state workers' compensation programs-employee and employer reports, medical reports, compensation award records, etc-were long recognised as potentially valuable sources of information about occupational injuries and illnesses. Most workers' compensation agencies, however, were primarily concerned with administering claims systems, and were not particularly concerned with availability and accuracy of industry, occupation, or injury and illness data. Additionally, states processing such data had different coding systems, sometimes with identical terms being defined differently.

States were urged to supply the desired information in machine readable form. The different classification systems and record formats, however, resulted in noncomparabilities and processing difficulties. The bureau revised the program to require participating states to use comparable record formats and classifications.

In 1976 the current structure of the supplementary 
data system was established, in cooperation with 27 states. The name was chosen from the part SDS plays of providing supplementary information to the annual survey of injuries and illnesses. Although the SDS does not affect the variations in coverage and reporting requirements among states, it requires that participating states provide prescribed data elements and use specific classification systems, standard record formats, and uniform procedures.

\section{Description of SDS}

The primary source of information for the SDS is the first report of injury or illness that employers and insurance carriers submit to state workers' compensation agencies. All jurisdictions, with the exception of Louisiana, require such reports. There are four basic types of information on the report. The first identifies the employer and permits classification of the case by industry and geographical location. The second lists characteristics of the employee such as age, sex, salary, and occupation. The third describes how the accident or exposure occurred, any objects or substances involved, the nature of the injury or illness, and the part of body affected. The fourth provides information on the workers' compensation carrier, possible disability, and other items needed to process the claim. Under 50-50 grant funding agreements, state agencies classify, code, and process the information from the various workers' compensation reports. Since employers, employees, or physicians must file such administrative reports under state regulations, the information does not constitute an additional burden on employers.

The prescribed data elements which must be uniformly defined and submitted by all participating states are:

State code

\begin{tabular}{|c|c|}
\hline & industry) \\
\hline Reference year & Nature of injury or illness \\
\hline Case number & Part of body affected \\
\hline $\begin{array}{c}\text { Year and month } \\
\text { of occurrence }\end{array}$ & Source of injury or illness \\
\hline Occupation & Type of accident or exposure \\
\hline Industry & Sex of employee \\
\hline
\end{tabular}

At their option, states may also submit other data elements, such as duration of service, extent of disability, indemnity compensation, and medical costs, some of which may be defined differently from state to state. For example, "duration of service" may refer to time with an employer, in a particular occupation, or in a particular job. The following optional items may be submitted by participating states.

Day of occurrence

Time of accident

Time workday began

Lapsed time
Associated object or substance

Age of employee

Duration of service

Weekly wages

Extent of disability

Type of insurance

Indemnity compensation

Medical payments

The indemnity and medical costs of a case are particularly important optional items. Workers' compensation programs indemnify injured or ill workers with income replacing cash benefits. These payments are awarded for deaths, disfigurements, permanent disabilities, and for temporary disabilities that exceed some specified number of days - that is, a waiting period. Medical expenses associated with an injury or illness are usually paid in full without a waiting period. Although indemnity compensation and medical payments data are useful economic and social indicators, and some measure of severity, only a few of the participating states can provide these data.

Classification systems used by all states in the SDS include: (1) The 1972 Standard Industrial Classification Manual to code industry; (2) the 1970 Bureau of the Census Alphabetical Index of Industries and Occupations to code the occupation of the injured or ill employee; (3) the American National Standards Institute Z16.2-1962 Method of Recording Basic Facts Relating to the Nature of Occurrence of Work Injuries (with codes expanded and modified by the bureau) to classify the nature of the injury or illness, the part of body affected, the source of the injury or illness, and the type of accident or exposure; and (4) a newly developed classification, the associated object or substance, which provides additional information about the factors associated with the injury or illness.

By applying the percentage distributions of the SDS data to annual survey data, it is possible to arrive at estimated numbers of injuries and illnesses on a national basis by various characteristics. Despite differences in the number of cases among states, the percentage distributions of injuries and illnesses are relatively consistent across the states-patterns that have been observed in several consecutive years of data from about 30 states. Observations, statistical tests, and the geographical and industrial diversity of the states support the hypothesis that these data are representative of the national experience. An example of how SDS data may be used in conjunction with the annual survey data follows: in 1979, disabling injuries or illnesses affecting the back accounted for $22.5 \%$ of all cases in the SDS program; the total number of lost workday injuries or illnesses collected through the annual survey was about $2.8 \mathrm{~m}$, resulting in a national estimate of 630000 disabling back injuries for the year $(22.5 \% \times 2.8 \mathrm{~m})$. 
I thank Patti Cournoyer for her painstaking accuracy in data collection and calculations. The research was carried out in part with the help of a National Science Foundation grant No SFS-8408293. Michael Sheetz provided valuable computer help. I alone bear responsibility for error.

\section{References}

1 Baker S, O'Neil B, Karpf RS. The injury fact book. Lexington, Mass: Lexington Books, DC Health, 1984:27.

2 Milton T. The paradox of the missing institute. Journal of Public Health Policy 1983;4:394-7.

3 Research summary. Occupational deaths declined in 1980. Monthly Labor Review 1980;105:49-52.

4 Baker SP, Samkoff JS, Fisher RS, van Buren CB. Fatal occupational injuries. JAMA 1982;248:692-7.

5 Leigh JP. New estimates of job-related death in 347 occupations. $J$ Occup Med 1987;29:510-9.

6 Root N, Sebastian D. BLS develops measure of job risk by occuration. Monthly Labor Review 1981;104:26-30.

7 US Department of Labor, BLS. Distribution of occupational employment in states and abroad. (Various issues.)

8 US Department of Labor, BLS. State profile of employment and unemployment. (Various issues.)

9 Marin A, Psacharopoulos G. The reward for risk in the labor market: evidence from the United Kingdom and a reconciliation with other studies. Journal of Political Economy 1982;90:827-53

10 Leigh JP, Folsom RN. Estimate of the value of accident avoidance at the job depend on the concavity of the equalizing differences curve. Quarterly Review of Economics and Business. 1984;24: 56-66.

11 Allen SG. An empirical model of work attendance, Review of Economics and Statistics 1981;63:77-87.

12 Viscusi WK. Employment hazards: an investigation of market performance. Cambridge Mass: Harvard University Press, 1979.

13 US Department of Labor, BLS. Occupational injury and illness rates by industry. (Various issues from the 1970s.)

14 Inter-University Consortium for Political and Social Research. Quality of employment survey, 1973, cross-section. Ann Arbor: University of Michigan Press, 1979.

15 Institute for Social Research. A panel study of income dynamics. procedures and tape codes. Ann Arbor: University of Michigan Press, 1974:312-21.

16 Gujarati D. Basic econometrics. New York: McGraw-Hill, 1978.

17 Wilcosky TC, Chambless LE. A comparison of direct adjustment and regression adjustment of epidemiologic measures, $J$ Chronic Dis 1985;38:849-56.

\section{Destruction of manuscripts}

From I July 1985 articles submitted for publication will not be returned. Authors whose papers are rejected will be advised of the decision and the manuscripts will be kept under security for three months to deal with any inquiries and then destroyed. 